\title{
Study on the Design Features of "Key Concepts in Chinese Thought and Culture" and Its Picture Book
}

\author{
Jie Zheng ${ }^{1,2, *}$
}

\author{
${ }^{1}$ School of Foreign Languages, Northwest University, Xi'an, Shaanxi 710127, China \\ ${ }^{2}$ School of Foreign Studies, Nanjing University, Nanjing, Jiangsu 210023, China \\ *Corresponding author. Email: bilex_jiezheng@163.com
}

\begin{abstract}
In order to realize discourse communication, terms go first. In order to realize term planning, design goes first. The terminological project named "Key Concepts in Chinese Thought and Culture" has displayed multifaceted traditional Chinese culture through channels such as online term bank, printed books for adults and children, which is also an important step for the practice of local knowledge and universal value. Its unique humanity and tradition are rarely found in the existing international term bank. This paper studies and evaluates the macro- and meso-design features of its term bank and picture book in terms of the three parameters, namely, term selection, term arrangement and term categorization.
\end{abstract}

Keywords: Key Concepts in Chinese Thought and Culture, terminography, design feature,

arrangement, category

\section{INTRODUCTION}

The terminological project named "Key Concepts in Chinese Thought and Culture" is the first large-scale independent translation and dissemination activity of terms in Chinese thought and culture" [1], and its unique humanity and tradition are rarely found in the existing international or Chinese term blank, which is a crucial step for "the localization of knowledge and the universalization of discourse with Chinese characteristic" [2]. The project demonstrates the essence of Chinese traditional culture in multiple dimensions in China and foreign countries through diversified communication channels such as online term blank (Key Concepts in Chinese Thought and Culture Network), printed term collection, cultural picture books, and academic seminars. As one of the results of the popularization and promotion of the terminology project, the picture book The Geographical Terminologies of China ("the picture book" for short hereafter) published in July 2018 is the first volume of the "Chinese Wisdom". The user-friendly design philosophy of "being specially designed for children" in the publication description has enabled the design features to be reflected in all

*Fund: 2018 Undergraduate Education Quality Improvement Project of Northwest University - "Evaluation of the Effect of EGP+ESP Blended Mode Applied in College English Teaching" (No. JX18083). dimensions of the online homogenous terminology blank. Based on the design feature theory of lexicography, this article compares the design features of the two terminology products of the project, namely, Key Concepts in Chinese Thought and Culture Network and the picture book, with a view to providing ideas for the planning and construction of national dictionaries and terminology blank, and the international communication of Chinese culture.

\section{DESIGN FEATURES}

The term "design" originated from design studies, and was introduced into lexicology by "Mufwene (1984), Hausmann \& Wiegand (1989), Stark (1996)" and other scholars [3] ${ }^{12-13}$. Tian Bing and Chen Guohua [4] ${ }^{13-24}$ discussed the design features of English learner's dictionaries from six aspects of "user", "target language", "genre", "function", "retrieval" and "structure", and also compared the macrostructure and microstructure of English advanced learner's dictionary. Based on the user survey, Wei Xiangqing et al. [3] characterized the design features of bilingual learner's dictionaries from the "content features", "structural features" and "technical features", among which the structural features could be divided into "overall structure", "macrostructure", "mesostructure" and "microstructure". Liu Qing [5] elaborated the 
macrostructure and microstructure of the term dictionary. Zheng Shupu and Ye Qisong [6] ${ }^{69-96}$ summarized the nine major parameters for the terminology dictionary: "subject", "item type", "time", application", "purpose", "language", "medium", "arrangement" and "description". The macrostructure of the dictionary reflects the vertical hierarchical characteristics between entries, while the mesostructure reflects the horizontal correlation between entries. The former ensures the level of the dictionary, while the latter constructs the integrity of the dictionary [3]. Liu Qing [5] ${ }^{152}$ described the macrostructure of terminological dictionaries as "term selection purpose", "determining the main structure of dictionaries" and "dealing with terminological phrases, polysemous words and homonyms". The definition of macrostructure by the above scholars can be summed up as the selection and arrangement of term selection. As far as the term dictionary is concerned, it means two parameters: term selection and term arrangement. The terms arrangement depends on the mesostructure to realize the overall relevance of the dictionary, and the category relationship is the embodiment of the mesostructure in the dictionary [7-10]. Based on the above-mentioned viewpoints, this paper takes the two macrostructure parameters - term selection and term arrangement and the parameters of the mesostructure - term category as the main research objects, and studies the design features of the picture book and Key Concepts in Chinese Thought and Culture Network.

\section{THE TERM SELECTION FEATURES OF "KEY CONCEPTS IN CHINESE THOUGHT AND CULTURE NETWORK" AND ITS PICTURE BOOK}

The purpose and scope of the term selection of Key Concepts in Chinese Thought and Culture
Network can be understood from its website, news reports and scholars' literature.

"Key Concepts in Chinese Thought and Culture" refer to concepts and cultural core words in the form of words or phrases created by the main body of the Chinese nation, condensing the Chinese humanistic spirit, thinking mode and values. [11]

"The project aims to sort out the terms in thought and culture that reflect the characteristics of Chinese traditional culture and the thinking methods of the nation, and embody China's core values. In the foreign exchange activities of government agencies, social organizations and media, it is required to spread the Chinese voice and tell Chinese stories, so that the world can learn more about China's national conditions, history and culture." [12]

The series of books on "Key Concepts in Chinese Thought and Culture" collects the key words of Chinese culture in various fields such as literature, history and philosophy", and "the core task is to sort out and translate the terms in thought and culture that can reflect the Chinese discourse system and core values. [13]

According to the description of the above website, the purpose of the term selection of "Key Concepts in Chinese Thought and Culture Network" is to facilitate the communication of Chinese traditional culture in the world. The scope of term selection covers the terms related to "思想" (thought) in the fields of humanities and social sciences in traditional Chinese culture, that is, being different from material culture and institutional culture at the core level of cultural structure" [14]. However, according to the author's incomplete statistics, the term selection scope of "Key Concepts in Chinese Thought and Culture Network" goes beyond "思想" (thought), as shown in "Table I" below.

TABLE I.

CULTURAL TERMS EXCEPT THOUGHT

\begin{tabular}{|l|l|}
\hline \multicolumn{1}{|c|}{ Cultural category } & \multicolumn{1}{c|}{ Terms } \\
\hline Material culture & Ding/Vessel, The Great Wall \\
\hline Regional culture & $\begin{array}{l}\text { Fortress / City, Metropolis, Capital of a Country, Huaxia, The Yellow River, Rivers and Mountains / } \\
\text { Country or State Power, Nine Zhou (Regions), Tianxia (All under Heaven) }\end{array}$ \\
\hline Institutional culture & $\begin{array}{l}\text { Rule by Law, Feudal System / Feudalism, Family-state / Country, Lord of the People / Democracy, The } \\
\text { Imperial Civil Examination System, Sheji (Gods of the Earth and the Five Grains), Imperial Academy, } \\
\text { Select and Recommend, Feudal Clan System } \\
\text { Lord / Nobility / Monarch, King, Junzi (Man of Virtue), Son of Heaven, The Fiery Emperor and the Yellow } \\
\text { Emperor / Emperor Yan and Emperor Huang }\end{array}$ \\
\hline Folk culture & $\begin{array}{l}\text { Nian /year, Dragon, Spring Festival, The Qingming Festiva, Baixi (All Performing Arts), The Chinese } \\
\text { Zodiac / Animal of the Year }\end{array}$ \\
\hline
\end{tabular}

From the perspective of terminology, the naming and term selection scope of "Key Concepts in Chinese Thought and Culture Network" seems to be generalized. However, as an organic aggregate of terms, it aims to serve the users, that is, the people in the world who do not know much about Chinese traditional culture. They do not have high requirements for the nature and definition of terms or culture, but they all want to know the essence of Chinese traditional culture. Of course, "思想 " 
(thought) is the core of culture. Therefore, the term bank takes the term "thought" as the main body, supplemented by cultural categories such as material, region, institutional culture and folk custom. Also, ideas do not exist independently, but are embodied and reflected in the cultural categories of material, region, institutional culture and folk custom. For example, the term "Ding" in material culture was a vessel to cook food and was also used as an important ritual object in ancient times. "Ding" was a vessel symbolizing the highest authority in an ancestral temple (The History of the Han Dynasty). Also, it was the ritual utensil of ancestral temple sacrifice. "Li (Rites / Social Norms)" is the core term of Confucianism. The "Spring Festival" is not only the most important festival in China since ancient times, but also "contains the ethical feelings, religious feelings and life consciousness of Chinese people, with profound historical connotation and rich festival and custom contents" [15]. It can be seen that the term selection standard of Key Concepts in Chinese Thought and Culture Network is based on culture of thought, supplemented by other cultural terms directly related to "thought".

The purpose and scope of the term selection in the picture book is as stated in the publication description. A total of 14 terms related to human geography, such as "The Yellow River, Rivers and Mountains / Country or State Power, Nine Zhou (Regions), Tianxia (All Under Heaven), Fortress / City, Metropolis, Capital of a Country" have been collected. And the main purpose is to introduce the traditional Chinese geographical concept to children and to popularize the knowledge of human geography. The children can explore the cultural significance behind the seemingly common terms. Compared with the term blank with a wide range of users and a wide range of cultural fields, the picture book takes the children as a specific user group with the theme of "human geography". Therefore, the selection of terms cannot completely copy the source term blank, but should be less and more precise, which is the objective design decision that can be made based on the user's cognitive perspective.

\section{TERM ARRANGEMENT FEATURES OF "KEY CONCEPTS IN CHINESE THOUGHT AND CUlTURE NETWORK" AND ITS PICTURE BOOK}

Different from the traditional way of compiling and publishing paper-based term collections, "Key
Concepts in Chinese Thought and Culture Network" directly designs and publishes the terms online for users' inquiry. It does not consider the design elements of the catalog or index, which can be understood from the editor's perspective. From the perspective of user cognition, it is convenient to query a term with a question, however, it will be confusing if there is no specific query target, or if users want to give an overview of Chinese thought and culture. There are three design elements to make up for the defect of this term arrangement. The first is to set the term recommendation column in the eye-catching part of the home page of the website, which mainly includes a term and an overview, with three related term prefixes attached on the right side; the second is to set the overview of "related terms" on the right side of each term detail page; and the third is to set hyperlinks within the entry for other terms contained in the term blank. The first element alleviates the confusion of users without specific query target, and the latter two elements use two kinds of nesting arrangement, which is the lexicographic representation of users' associative thinking. These three design elements take into account the cognitive needs of users, improve the convenience of retrieval, and assist structural features through technical features.

The picture book aims at young users, and has made great efforts in the arrangement of terms. Taking history as the longitude, the Yellow River and the Yangtze River as the latitude, there are many humanistic geographical terms, presenting the world outlook of the unity of man and nature since the pre-Qin Dynasty. The concept category is progressive from the metaphysical to the physical, and from the abstract to the concrete. It begins with the extremely abstract and difficult words "universe" and "world". And then, it takes "Jiuzhou" which is the old name for China in the ancient times as the center, gradually focuses on the geographical coordinates "Forbidden City" that children are familiar with, and finally introduces the terms of "Beijing quadrangle" and "Hutong" in daily life. This term arrangement shows the editor's profound education and strong humanistic feelings, and also fits children's cognitive characteristics. The detailed introduction pages of dangdang.com and jingdong.com show the world outlook of "integrity", "order" and "harmony consciousness". (as shown in "Fig. 1") 


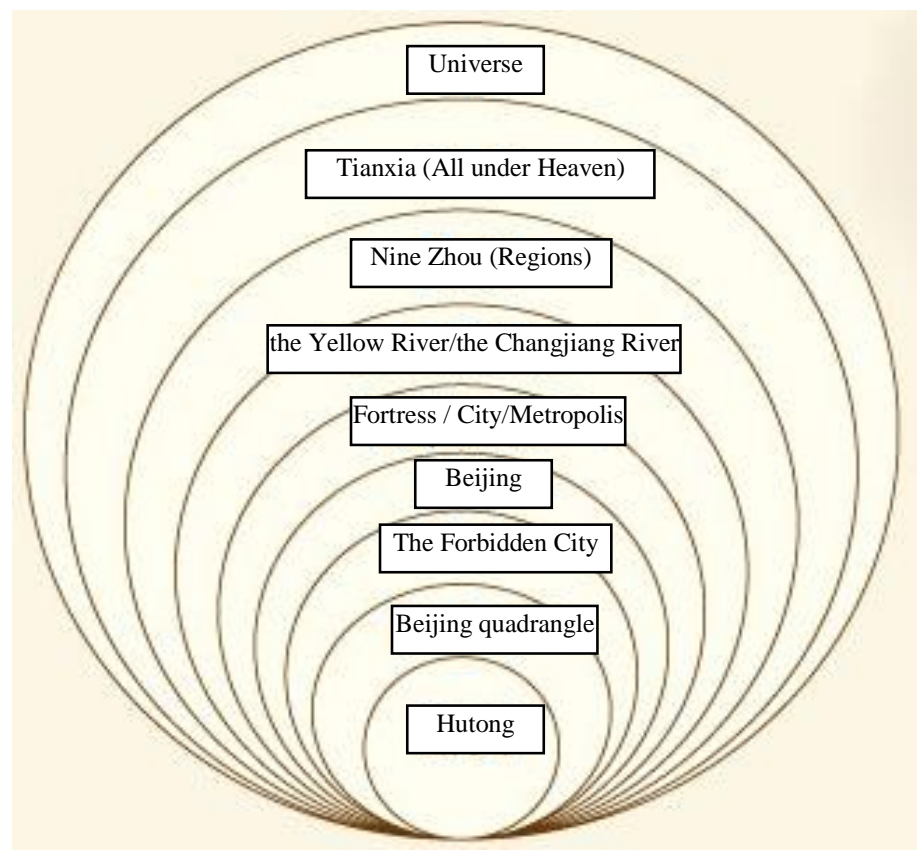

Fig. 1. Term arrangement of the picture book.

\section{CATEgORY FEATURES OF TERMS IN "KEY CONCEPTS IN CHINESE THOUGHT AND CULTURE NETWORK" AND ITS PICTURE BOOK}

The above two sections deal with the macrostructure of dictionaries. In order to build a dictionary structure system that conforms to the "integrity principle", "hierarchical principle" and "dynamic principle" of modern system theory $[3]^{179}$, mesostructure is necessary. [3] ${ }^{179}$. Zhang Yihua [16], [17] concretized the mesostructure as "category relation", summarized three development stages of category research applied to definition, namely, "classical category theory, prototype category theory and schema category theory", and proposed a "theoretical model of definition based on the relationship between category schemata and instantiations". According to the investigation of the structural characteristics of "Key Concepts in Chinese Thought and Culture Network" and its picture book, it shows that the relationship among the members of each term category includes not only the glossematic relations and semantic relations of the traditional mainstream dictionaries, but also the conceptual relationships such as logical relations. The latter is a great innovation of dictionary design from the perspective of user cognition, and plays an important role in the construction of learners' knowledge ontology.

The term category relationship of "Key Concepts in Chinese Thought and Culture Network" is embodied in the collection of relevant items (referring to category members) with each term as the core (referring to category word). They together constitute the category of thought and culture in China, reflecting the combination of terminology and epistemology. At the same time, these categories are just the elements to construct the mesostructure which accords with the psychological representation of users. The category relations of "Key Concepts in Chinese Thought and Culture Network" mainly include syntagmatic relation, hierarchical relationship, near-synonymy relationship, antonymy, associative relationship, causality / conditional relationship and overlapping relationship. If "Kingly Way (Benevolent Governance)" is taken as a category word, there are 16 category members, and the category relationship with the term "Kingly Way (Benevolent Governance)" is shown in "Table II". 
TABLE II. "KINGLY WAY (BENEVOLENT GOVERNANCE)" CATEGORY RELATIONSHIP

\begin{tabular}{|c|c|c|c|c|c|c|c|c|}
\hline & & $\begin{array}{l}\text { Syntagmatic } \\
\text { relation }\end{array}$ & $\begin{array}{l}\text { Hierarchical } \\
\text { relationship }\end{array}$ & \begin{tabular}{|l|} 
Near- \\
synonymy \\
relationship
\end{tabular} & \begin{tabular}{|l|} 
Antonymy \\
relationship
\end{tabular} & $\begin{array}{l}\text { Associative } \\
\text { relationship }\end{array}$ & $\begin{array}{l}\text { Causal/conditional } \\
\text { relationship }\end{array}$ & $\begin{array}{l}\text { Overlapping } \\
\text { relationship }\end{array}$ \\
\hline \multirow{16}{*}{$\begin{array}{l}\text { Category } \\
\text { word "Kingly } \\
\text { Way } \\
\text { (Benevolent } \\
\text { Governance)" }\end{array}$} & King & $\sqrt{ }$ & & & & $\sqrt{ }$ & & $\sqrt{ }$ \\
\hline & \begin{tabular}{|l|} 
Protect the \\
People and then \\
Rule as a King \\
\end{tabular} & $\sqrt{ }$ & & & & $\sqrt{ }$ & & $\sqrt{ }$ \\
\hline & \begin{tabular}{|l|} 
Love the People \\
\end{tabular} & & $\sqrt{ }$ & & & $\sqrt{ }$ & & $\sqrt{ }$ \\
\hline & \begin{tabular}{|l}
$\begin{array}{l}\text { Benefit the } \\
\text { People }\end{array}$ \\
\end{tabular} & & $\sqrt{ }$ & & & $\sqrt{ }$ & & $\sqrt{ }$ \\
\hline & \begin{tabular}{|l|}
$\begin{array}{l}\text { Nurturing the } \\
\text { People }\end{array}$ \\
\end{tabular} & & $\sqrt{ }$ & & & $\sqrt{ }$ & & $\sqrt{ }$ \\
\hline & $\begin{array}{l}\text { Will of the } \\
\text { People }\end{array}$ & & & & & $\sqrt{ }$ & $\sqrt{ }$ & \\
\hline & \begin{tabular}{|l|} 
Governance \\
Based on Virtue
\end{tabular} & & & $\sqrt{ }$ & & $\sqrt{ }$ & & $\sqrt{ }$ \\
\hline & $\begin{array}{l}\text { Embrace Distant } \\
\text { Peoples by } \\
\text { Means of Virtue }\end{array}$ & & & & & $\sqrt{ }$ & & $\sqrt{ }$ \\
\hline & $\begin{array}{l}\text { Power Comes } \\
\text { from Caring for } \\
\text { the People }\end{array}$ & & & $\sqrt{ }$ & & $\sqrt{ }$ & & $\sqrt{ }$ \\
\hline & $\begin{array}{l}\text { People Being } \\
\text { the Foundation } \\
\text { of the State }\end{array}$ & & & & & $\sqrt{ }$ & $\sqrt{ }$ & \\
\hline & $\begin{array}{l}\text { The People's } \\
\text { Will Is the } \\
\begin{array}{l}\text { Foundation of } \\
\text { the State }\end{array} \\
\end{array}$ & & & & & $\sqrt{ }$ & $\sqrt{ }$ & \\
\hline & $\begin{array}{l}\text { All People Are } \\
\text { My Brothers and } \\
\text { Sisters, and All } \\
\text { Things Are My } \\
\text { Companions }\end{array}$ & & & & & $\sqrt{ }$ & $\sqrt{ }$ & $\sqrt{ }$ \\
\hline & $\begin{array}{ll}\text { Have Love for } \\
\text { the People, and } \\
\text { Cherish All } \\
\text { Things }\end{array}$ & & & & & $\sqrt{ }$ & & V \\
\hline & $\begin{array}{l}\text { Follow the } \\
\text { Mandate of } \\
\text { Heaven and } \\
\text { Comply with the } \\
\text { Wishes of the } \\
\text { People }\end{array}$ & & & & & & $\sqrt{ }$ & \\
\hline & $\begin{array}{l}\text { Never Forget the } \\
\text { Suffering of the } \\
\text { People }\end{array}$ & & & & & & & $\sqrt{ }$ \\
\hline & \begin{tabular}{l}
\multicolumn{2}{|l}{ Those Who Rely } \\
on Virtue Will \\
Thrive; Those \\
Who Rely on \\
Force r Will \\
Perish
\end{tabular} & & & & & & & V \\
\hline
\end{tabular}

The category word "Kingly Way (Benevolent Governance)" covers $85.7 \%$ of the seven category relations in the "Table II", only the antonym relation is not covered, and all the related terms form associative relationship. There are 10 members in "Li" category and 13 members in "Ren" category. The coverage rate of these two categories is $71.4 \%$, neither of them covers homonymy / synonymy or antonymy. The category member "villain" has an antonym relationship with "Junzi". The traditional Chinese dictionaries set the user-friendly features mainly from the perspective of glossematics. The mesostructure of the term blank is based on the conceptual relationship and the direction is the construction of the user's domain knowledge system.

The category relations of terms in the picture book reflect different cognitive domains. As can be seen from the term arrangement above, the terms of the whole picture book is skillfully connected, which is permeated with the world outlook of the unity of man and nature. What is more important is 
that users can identify different categories from different cognitive domains; at the mesostructure level, each category has a category prototype and category examples at different levels, which constitute hierarchical and associative relationships. If the core term "city" is taken as the "category prototype", "Metropolis" or "Capital of a Country" is its category example or hyponymic term, followed by Luoyang, Xi'an, Kaifeng, Nanjing (the ancient capitals of the Yellow River Basin), and Beijing (the ancient capital of the Yangtze River
Basin). The promotion of terms is mainly based on the spatial domain, that is, taking the Yellow River and Yangtze River as geographical coordinates, supplemented by time domain, namely, the change of dynasties in which the capital was established. According to the above ideas, the author draws the following "Fig. 2", which shows the hierarchical relationship of the prototype "city" and its category examples, as well as the associative relationship between time and space.

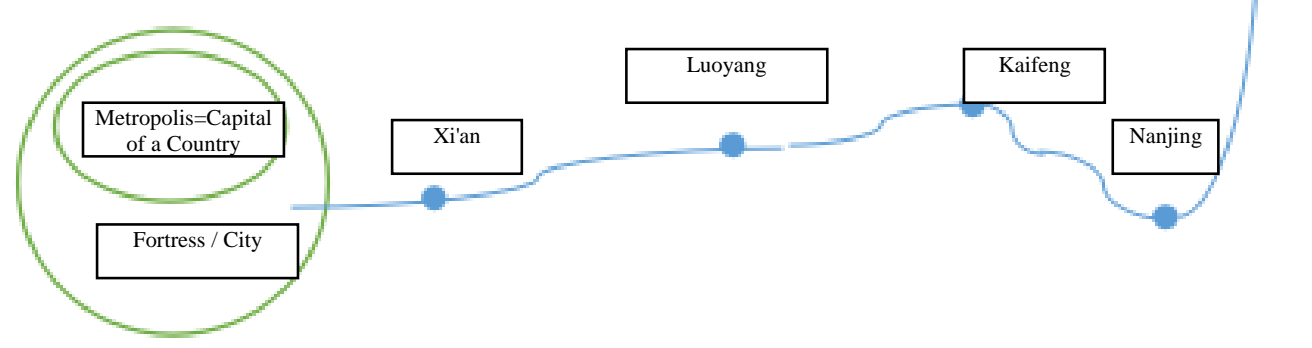

Fig. 2. "Fortress / City" category in the picture book.

\section{CONCLUSION}

The essence of terminography is knowledge organization $\quad[18][19]^{15}$. Cross-lingual terminography is one of the important national knowledge organization practices, and design is the key link. The particularity of terms and users should be considered. "The heterogeneity of language symbols, the locality of knowledge system and the uniqueness of cultural tradition" bring challenges to the knowledge practice of discourse with Chinese characteristics $[20]^{105}$. Among them, the uniqueness of cultural tradition is reflected in four aspects: the particularity of humanities and social sciences terms compared with natural science terms [21], [22], the "multiple characteristics" and "unique cultural geneticity" of the terms in thought and culture compared with other cultural category terms, the "historicity" and "interpretative context" of traditional Chinese terms in thought and culture compared with contemporary terms in thought and culture $[1]^{67-68}$, and the collision and blending of "local knowledge" and "universal value" [2] $]^{93-94}$. In view of the above particularity, the design of terminological products should be combined with the cognitive characteristics and cognitive needs of specific user groups, and corresponding design concepts and methods should be adopted. At the height of macrostructure and mesostructure, the planners and compilers of "Key Concepts in Chinese Thought and Culture" try to build a systematic crosslanguage knowledge organization platform from the perspective of users' cognition. The relationship between "Key Concepts in Chinese Thought and Culture Network" and the picture book is like the relationship between mother and son, and the corpus comes from the same source. However, considering the cognitive characteristics of different user groups, there are differences in the design.

The term selection should be different according to the target users, and fit in with their mental lexicon and cognitive characteristics. The purpose of "Key Concepts in Chinese Thought and Culture Network" is to make the world better understand China's national conditions, history and culture. With the vast number of users, its terms should cover a wide range and reflect the essence of Chinese traditional culture. Therefore, its terms are centered on the culture of thought, supplemented by other cultural terms directly related to ideas. The picture book is specially designed for children, with the theme of human geography, and the term selection should be refined. How to extract the source data pertinently requires the core team of terminography to have deep humanistic and geographical literacy and rich experience in lowage education.

A reasonable arrangement of terms is based on a full grasp of users' psychology and cognition, and can also effectively promote users' cognitive behavior. "Key Concepts in Chinese Thought and Culture Network" is designed and launched online directly, without considering the design elements of the catalog or index. Although this defect is made 
up to a certain extent through terms recommendation, related terms and hyperlinks, the user-friendly catalog or index is worth looking forward to. The picture book design integrates the world outlook of the unity of man and nature into the term arrangement. And term arrangement is from large to small and from abstract to specific, breaking the stereotype and connecting the boring terms.

Category is the key link in the construction of mesostructure of terminological products. Based on the conceptual relationships between category words and category members, "Key Concepts in Chinese Thought and Culture Network" constructs the mesostructure with the purpose of constructing users' domain knowledge system. Each category in the picture book has a "category prototype" and multiple levels of "category examples", which jointly constitute the hierarchical relationship and association relationship. The promotion of terms is mainly based on the spatial domain, that is, taking the Yellow River and Yangtze River as geographical coordinates, supplemented by the time domain, namely, the changes of the capital. Each term can find its category, and each term can activate the user's psychological representation of next term. As Dangdang and Jingdong and other online business detail pages said, "With the use of the 'association method' to connect the historical stories, children can better think about the nature of things and deepen the internal relations."

"In order to realize discourse communication, terms go first" [2] ${ }^{97}$. In order to realize term planning, design goes first." The multi-dimensional design concept and communication concept of "Key Concepts in Chinese Thought and Culture" is an important step in the integration of local knowledge and universal value. It is required to refine the user groups and carry out the corresponding user survey, so as to realize the future design update or planning. For example, Bergenholtz \& Tarp $[23]^{19}$, a specialist lexicographer, divides three user groups into experts, semi experts and laymen, and points out that the cognitive function and communicative function of dictionaries should be combined with the language level and professional knowledge level of specific user groups. On the other hand, it is necessary to study the effective knowledge organization mode of Chinese cross-lingual terminography more systematacially, so as to meet the cognitive needs of multi-level users.

\section{References}

[1] Wei Xiangqing. On Translating the Terms of Chinese Culture into English: its Practical Rationality and Basic Principle [J]. Foreign Language Research, 2018,35(03): 66-71. (in Chinese)
[2] Wei Xiangqing, Yang Ping. External communication of Chinese characteristic discourse and terminology translation standardization[J]. Chinese Translators Journal, 2019,40(01): 91-97. (in Chinese)

[3] Wei Xiangqing, Geng Yundong, Lu Huaguo. Research on the Design Features of Bilingual Learner's Dictionary [M]. Beijing: Foreign Language Teaching and Research Press, 2014. (in Chinese)

[4] Tian Bing, Chen Guohua. Research on the Design Features of English Advanced Learner's Dictionary and the Cognitive Semantic Structure and Semantic Features of Polysemous Words [M]. Beijing: Science Press, 2009. (in Chinese)

[5] Liu Qing. Introduction to Chinese Terminology [M]. Beijing: The Commercial Press, 2015. (in Chinese)

[6] Zheng Shupu, Ye Qisong. On Terminography [M]. Shanghai: Shanghai Lexicographical Publishing House, 2015. (in Chinese)

[7] Zhang Yihua. Lexical Relatedness and Modes of Definition Based on the Prototype and Schema Category Theories:A Case of Categorization-based Definition [J]. Lexicographical Studies, 2017(05): 1-12. (in Chinese)

[8] Zhang Yihua. Defining the commonalities and differences based on the relation between category schemata and instantiations: Categorized lexical definitions for the English learner's dictionary $[\mathrm{J}]$. Foreign Language Teaching and Research, 2017,49(02): 240-253. (in Chinese)

[9] Zhang Yihua. Constructing the mediostructure and its network in learner's dictionaries [J]. Modern Foreign Languages, 2008(04): 360-368. (in Chinese)

[10] Zhang Yihua. Analysis on the utility of the mediostructure network in the learner's dictionary - on the basic structure system and function of the learner's dictionary. The 7th National Bilingual Dictionary Symposium of Chinalex Bilingual Dictionary Committee [C]. Chongqing, China, 2007. (in Chinese)

[11] Key Concepts in Chinese Thought and Culture. "A Collection of Academic Papers on Key Concepts in Chinese Thought and Culture (First Series)" [EB/OL]. [2018-09-26].

http://www.chinesethought.cn/detail.aspx $?$ nid=92\&pid=13 $3 \&$ id $=3985$.

[12] Key Concepts in Chinese Thought and Culture. Introduction to Project named "Key Concepts in Chinese Thought and Culture" [EB/OL]. [2018-09-26]. http://www.chinesethought.cn/single.aspx $?$ nid=95\&pid=99

[13] Xinhuanet. "Key Concepts in Chinese Thought and Culture" (Sixth Series) published in Beijing [EB/OL]. [2018-09-26]. http://www.xinhuanet.com/book/201808/15/c_129933453.htm.

[14] He Xiaoming. "Ideological Orientation" and "Cultural Character" in the Study of Ideological and Cultural History [J]. History Monthly, 2017(09): 10-13. (in Chinese)

[15] Key Concepts in Chinese Thought and Culture. Spring Festival [EB/OL]. [2018-09-26]. http://www.chinesethought.cn/shuyu_show.aspx?shuyu_id $=4053$.

[16] Deng Lin. A Review of Studies on Dictionary Definition Based on Prototype Theory [J]. Lexicographical Studies, 2016(02): 27-32. (in Chinese)

[17] Zhang Yihua. Second Language Acquisition And Learner's Dictionaries [M]. Beijing: The Commercial Press, 2014. (in Chinese)

[18] Zheng Jie. On the Isomorphism Between Knowledge Organization and Terminography $[\mathrm{J}]$. Library Theory and Practice, 2020(02): 85-89. (in Chinese) 
[19] Zheng Jie. A New Interpretation Of Terminography From The Perspective Of Knowledge Organization [J]. China Terminology, 2020, 22(04): 12-17. (in Chinese)

[20] Liu Runze, Ding Jie, Liu Kai. The Innovative Practice and Methodological Significance of the Standardization of Term Bank with Chinese Characteristics [J]. Chinese Translators Journal, 2019,40(01): 104-110. (in Chinese)

[21] Wei Xiangqing. Internationalization and Nationalization: Thoughts on Translation Strategy of Terms in Humanities and Social Sciences [J]. Nanjing Social Sciences, 2010(05): 116-121. (in Chinese)

[22] Wei Xiangqing. On the Basic Features of Term Translation in Humanities and Social Sciences [J]. Foreign Languages Research, 2010(06): 165-167. (in Chinese)

[23] Bergenholtz H, Tarp S. Manual of Specialised Lexicography: The preparation of specialised dictionaries[M]. John Benjamins, 1995. 